\title{
Sexualidade J uvenil: Vivências nas Ocupações do Movimento dos Sem Teto da Bahia
}

\author{
Youth Sexuality: Experiences in the Occupations of Bahia Homeless Movement
}

\author{
Helaine Pereira Souza \\ Universidade Católica do \\ Salvador \\ helainep.souza@hotmail.com
}

\section{Resumo}

O Movimento dos Sem Tetos de Salvador (MSTS), que mais tarde adotará a sigla MSTB (Movimento dos Sem Tetos da Bahia) surge em junho do ano de 2003, após ocupação na capital baiana. Aponta-se como uma forma de resistência no espaço urbano, que busca não apenas um "teto" particular, mas sim a constituição de "comunidades de bem viver". O Movimento caracteriza-se como resposta à violação do direito de moradia. $\mathrm{O}$ presente trabalho busca relatar as experiências das jovens que foram mães na adolescência do Movimento, mostrando as participações no MSTB bem como suas trajetórias e expectativas como jovens gestantes, como atuam em um espaço marcado pela constante mobilidade. Algumas questões foram levantadas a fim de discutir como jovens em situação de vulnerabilidade exercem sua sexualidade.

Palavras-chave: juventude; sexualidade; luta por moradia.

\begin{abstract}
The Salvador Homeless Movement (MSTS), that later adopted the acronym MSTB (The Salvador Homeless Movement), appeared in Salvador in June of 2003, after occupying the capital of Bahia. It has been mentioned as a form of resistance in urban areas, seeking not only a private "ceiling", but rather the creation of "communities of living well." The Movement is characterized as a response to the violation of housing rights. This study aims to report the experiences of young women who were adolescent mothers during the movement, showing the participation at MSTB as well as their trajectories and expectations as young pregnant women and the way they behave in an area marked by constant mobility. Some questions were raised in order to discuss how young people in vulnerable situations exercise their sexuality.
\end{abstract}

Keywords: youth; sexuality; housing struggle. 


\section{Introdução}

A contemporaneidade reserva papéis de destaque à sexualidade juvenil. Freqüentemente caracterizada como 'desregrada' e associada à ausência de vínculos. Por tanto, sobre ela deve pesar o controle. E muitas dessas visões, baseadas em análises biológicas ou enfoques na imaturidade do ser jovem, não permitem que o exercício da sexualidade seja entendido como construção da identidade, do sentimento de pertença a determinado grupo ou ainda como rito de passagem.

É partindo da necessidade de entender as experiências sexuais de uma juventude vulnerabilizada, que nos propomos a dar voz as jovens mulheres do Movimento dos Sem Teto da Bahia essas mulheres, permitindo que do seu lugar, narrem sobre a experiência de uma gravidez na adolescência, as vivências enquanto militantes de um movimento social urbano.

\section{Juventude e Sexualidade: Controle, Identidade, Autonomia?}

Cresce, na contemporaneidade, a atenção voltada para a juventude. Foco que ocorre de maneira dual, ora se dá pela exaltação do que é jovem e associasse a juventude vitalidade, modernidade e o que há de belo. Ora criminaliza-se, fazendo conexões com números do tráfico e consumo de drogas, violência e a ausência de planejamento para o futuro.

Tais abordagens estariam plantadas na tentativa de singularizar a juventude, não atentando para as diferenças:

$\mathrm{Na}$ verdade, nas representações correntes da juventude, os jovens são tomados como fazendo parte de uma cultura juvenil «unitária». No entanto, a questão central que se coloca à sociologia da juventude é a de explorar não apenas as possíveis ou relativas similaridades entre jovens ou grupos sociais de jovens (em termos de situações, expectativas, aspirações, consumos culturais, por exemplo), mas também -e principalmente - as diferenças sociais que entre eles existem. (PAIS, 1990, p. 140)

O primeiro desafio que surge ao se falar de juventude é a delimitação dos marcos de definição do que é ser jovem. Castro e Abramovay indicam que "entre as diversas possibilidades de interpretação teórica a respeito da juventude, há uma possibilidade mais recente que descarta parcialmente os marcos etários, dando centralidade à categoria sociológica e autoidentitária do jovem" (2010, p. 31).

Ao mesmo tempo, que esta marcação cronológica é um importante marcador social. Em virtude que é a partir desses conceitos que é estabelecido "o acesso individual a direitos e deveres político-jurídicos. Os indivíduos e sua ordem de nascimento são as unidades básicas de referência para a relação entre o Estado Moderno e os sujeitos sociais" (ALVES, 2004, p. 358). No cotidiano, esses marcos etários podem ser visualizados de maneira diferente para os grupos sociais.

Para o conjunto da sociedade brasileira, a tendência maior é a de antecipação do início da vida juvenil para antes dos 15 anos, na medida em que certas características de autonomia e inserção em atividades no mundo do trabalho - típicas do momento definido como de transição da situação de dependência da criança para a autonomia completa do adulto - tornam-se o horizonte imediato para grande parcela dos setores empobrecidos. (SPOSITO, 1999b, p. 39)

São frequentes as caracterizações dos jovens como apáticos. Em outras "os segmentos juvenis têm sido caracterizados, nas últimas décadas, pela extrema acentuação de seus traços individualistas, pela apatia política e pelo desinteresse nas relações com a esfera pública" (SPOSITO, 1999a, p. 77). Longe de acreditar numa atitude narcísica, advogamos que os jovens têm buscado novas formas de associação.

A juventude se tornou foco privilegiado dos movimentos sociais. Considerando-se as rápidas transformações nas condições de vida dos grupos humanos na fase contemporânea do capitalismo, a adrenalina juvenil é canalizada de forma construtiva para alguns e por outros de forma perigosa para a sociedade (CASTRO e ABRAMOVAY, 2002, p. 31).

Essas novas formas de atuação aparecem em reposta à negação a participação política tradicional. Nesse contexto, emerge aproximações artísticas culturais como grupos de hip hop, grafite, trabalhos comunitários, produção de vídeos, rádios comunitárias, redes virtuais (SPOSITO, 1999a; CASTRO e ABRAMOVAY, 2010).

São os passeios de bicicleta, as caminhadas,

Helaine Pereira Souza 
os grupos de skate e de escalada em viadutos e pontes que negam o valor de troca predominante no espaço urbano e os ritmos da metrópole voltada para o circuito de reprodução do capital, afirmando a dimensão pública da cidade a partir do uso e da fruição. Outra modalidade de experiência coletiva entre jovens que emerge com maior frequência tem sido um certo associativismo em torno de ações voluntárias, comunitárias ou de solidariedade, compreendendo temas diversos como o combate à exclusão, meio ambiente, qualidade de vida e saúde (informação sobre consumo de drogas, DST e AIDS). (SPOSITO, 1999a, p.80)

Castro e Abramovay (2005, p. 65) salientam que os jovens não são apenas uma população em estado de vulneralibilidade, mais do que isso, seria uma geração vulnerabilizada, em especial se são pobres, já que nesta condição "vulnerabilidades se reproduzem e se combinam, limitando também o estatuto de sujeitos de direitos e suas potencialidades para serem atores/atrizes do desenvolvimento."

Uma pessoa pode tornar-se menos vulnerável se for capaz de reinterpretar criticamente mensagens sociais que a colocam em situações de desvantagem ou desproteção, mas sua vulnerabilidade pode aumentar se a mesma não tem oportunidades de resigificar as mensagens emitidas no seu entorno (VILLELA e DORETO, 2006, p.2469)

Acrescentando sobre essa assertiva, Castro e Abramovay vão mais além e trazem ao debate o conceito de vulnerabilidade positiva, atitudes que na adultocracia podem ser vistas de maneira negativa, mas que, contudo remodela o protagonismo juvenil.

Vulnerabilidades positivas também abrangem questões que comumente são associadas por adultos a negatividades, mas que podem potencializar mudanças civilizatórias e engajamentos positivos, fazer a diferença. É quando se traz para debate outro enfoque: a participação dos próprios jovens, por vetores que não se confundam com o clientelismo ou manipulação política, mas se equaciona com acessibilidade a distintos recursos, inclusive o de fazer e de mudar o fazer política. $\mathrm{O}$ agito, a rebelião, é uma das possíveis vulnerabilidades positivas - formas de ser ou de buscar dos jovens, entendidas muitas vezes, pelos adultos com negativas, mas que colaboram para singularizar processos de afirmação. (CASTRO e ABRAMOVAY, 2005, p. 56)

É preciso avançar na compreensão de juventude, entendendo que esta não se encontra isolada. As gerações, como outras categorias, não existem isoladamente, mas em referência mútua, contraposição ou até oposição umas às outras. Uma geração é ou se torna aquilo que o jogo de poder permite nas relações umas com as outras. "Cada momento histórico se realiza com a presença simultânea de várias gerações que, mesmo contemporâneas, não têm as mesmas experiências e trajetórias de vida." (MOTA, 2004, p. 351).

Entretanto, se o 'mundo adulto' não proporciona a inserção dessa juventude e de alguma maneira (ou muitas) marginaliza-a, é por meio do aprendizado por pares, a fratria, que as/os jovens têm amplas formas de socialização, no entanto os valores podem ser resignificado de acordo com padrões próprios, como bem reflete o funk carioca "Não somos fora da lei, porque a lei quem faz é nós". (Mc Orelha - Vermelho tipo Faixa de Gaza).

O problema da turma [de jovens] é que quando a sociedade não estabelece limites claros (ainda que inconscientes!) para o gozo, a turma adolescente pode transformase em gangue e os testes de liberdade amparados pela cumplicidade dos amigos podem descambar para a autorização aos atos de delinqüência. A 'fratria' ampara aqueles que estão saído do mundinho protegido da família e ingressando no vasto mundo da cultura, das democracias; é a força de coesão, decisão e pressão dos irmãos que faz a democracia funcionar, e não a autoridade isolada do 'pai' ou do chefe político. Mas, por isso mesmo, desligada de referências coletivas, a fratria pode se acreditar no direito de 'fazer a própria lei' e ingressar na vida da criminalidade. (KEHL, 2004 In CASTRO e ABRAMOVAY, 2005)

Essa identificação por pares forja um sentimento de pertencimento "que dão vazão às mais variadas formas de expressão de pertencimento grupal, atingindo modificações inusitadas até do próprio corpo" (MOTA, 2004, p. 352). 
Nesse prisma cultural, para a juventude o despertar da sexualidade pode ser vista com a aquisição de autonomia, aceitação entre os pares e inserção no mundo adulto. "A sexualidade é uma das dimensões básicas nas constituições de caminhos identitários, representada para os jovens como espaço de construção de autonomia, de separação da casa, da família." (CASTRO, MIRANDA e ALMEIDA, 2007). Villela e Doreto (2006) avaliam que o exercício da sexualidade assume sentidos distintos para cada pessoa "que, talvez só tenha em comum o fato de terem nascido num mesmo período de tempo". A sexualidade precisa ser vista como ação humana e portando uma produção sociocultural (VALE, 2008).

Sendo assim, a maneira como a gravidez na adolescência $^{1}$ é percebida também é distinta e variante de acordo com o extrato da população. Na categoria de classes, as perspectivas de juventude, gênero e sexualidade são visualizadas de formas próprias.

Não estamos diante de um fenômeno novo, mas como apontado por Heilborn et at. (2002), a visibilidade dá-se em função que a fecundidade na adolescência esta na contramão da demografia populacional, que registra queda no número de nascimentos. E as muda-se as concepções de gênero e geração, no seio da sociedade. O prolongamento da juventude deposita nos jovens maiores expectativas quanto seu futuro, que devem estar voltados para a escolarização, profissionalização e, portanto protelando a idade para exercer a maternidade e a paternidade, já que a sexualidade foi desvinculada da reprodução. Por tanto há razões históricas e sociais para a atenção que o fenômeno vem ganhando.

No entanto, essas novas oportunidades que o prolongamento da juventude proporciona é mais sentido nos extratos médios da população, para as classes com menos renda, a realidade é outra. Esses têm suas trajetórias escolares marcados por evasões. Por motivos que divergem de acordo com a categoria gênero. Para o masculino marcado pela necessidade inserção no mercado de trabalho, que garanta uma renda própria. E para o feminino, as obrigações com as atividades domésticas, cuidado com os irmãos menores.

Ao se falar em gravidez na adolescência, algumas opiniões estão cristalizadas no imaginário coletivo, de imediato associa-se ao abandono escolar, agravamento da pobreza, incapacidade física e psíquica de exercer a maternidade. Para Sabroza et al. (2004), a gravidez nesse período impõe uma responsabilidade precoce, somado a instabilidade das relações conjugais e um ambiente familiar pouco acolhedor em reposta ao anuncio da gestação resulta em repercussões emocionais negativas.
Porém, vertente como esta negligenciam que para algumas jovens a gravidez na adolescência pode significar uma alternativa de vida. E, portanto, ignorase a autonomia dos adolescentes, até porque a opção pela interrupção da gravidez existe. Sendo assim "Talvez a gravidez não seja um problema, e sim uma solução, um meio de aquisição de identidade e função social" (VILLELA e DORETO, 2006, p. 2469). Dessa forma alertar-se para autonomia, tão incentivada, dos adolescentes. Esses devem ser entendidos como sujeitos de direitos (CASTRO, RIBEIRO e BUSSON, 2010). O Estatuto da Criança e do adolescente não se refere a sexo, ou ao exercício da sexualidade. Assim como o Direito brasileiro que "considera a tutela da sexualidade de crianças e adolescentes apenas pelo viés repressivo, voltando à responsabilização dos agressores" (MELO, 2010, p. 17)

Para Pantoja (2002), os meios de comunicação têm contribuído para a visibilidade do fenômeno, entretanto com um discurso alarmista. Ignora-se que a gravidez na adolescência possa representar um sonho concretizado. Em seu estudo, a autora analise que o chá de bebê teria um caráter social e seria elucidante de como a gravidez pode ser visualizada de maneira positiva

A sexualidade é exercida de modos opostos, no geral o adolescente do sexo masculino tem exercício da sexualidade estimulado, o que não ocorre com a adolescente do sexo feminino. Por tanto, ao contrário do estigma de uma sexualidade juvenil aleatória, estudos mostram que a gravidez na adolescência tende a ocorrer em reações de namoro, e não no ato de 'ficar'2 como tal vertente presumiria. (BORGES e SHOR, 2005).

Nos estudos sobre gravidez na adolescência, a perspectiva do materno é privilegiada (HEILBORN et al., 2002). É preciso atentar que o fato tem dois protagonistas e "que excluímos e isentamos de responsabilidade os rapazes e os homens, acentuamos as desigualdades entre os sexos, restringimos as hipóteses de sucesso das estratégias de prevenção" (MARQUES, 2007, p. 14).

Em geral, os parceiros costumam ser mais velhos do que as adolescentes, o que chama atenção para diferenciação do engravidar alguém na adolescência, do engravidar alguém adolescente. "As gravidezes das adolescentes não resultam, necessariamente, de relações sexuais com adolescentes ou indivíduos de idades aproximadas" (MARQUES, 2002, p. 22).

Para Chalem et al (2007, p.184), há, nas classes populares "uma pressão para que o casal formalize uma união e passe a conviver sob o mesmo teto.". Sendo assim, a gravidez pode resultar numa coabitação, e mesmo que isso não ocorra não significa

Helaine Pereira Souza 
que é o fim do namoro.

Há de se questionar o papel da informação e prevenção, uma vez que essa geração nasce sobre um significativo no número de pessoas portadoras do vírus da AIDS, sendo que já se torna difícil apontar um grupo de risco, uma vez que a síndrome se espalha alarmantemente entre os gêneros e gerações. Neste tocante, observa-se que quanto mais precoce a iniciação e menor a escolaridade, maiores são as chances de não uso de métodos contraceptivos (CABRAL, 2003).

O uso de contraceptivos não está ligado a diretamente ao conhecimento dos adolescentes, este teria outros determinantes, apontando para uma má informação, somada ao que denomina por crenças errôneas e ao papel da família (ALMEIDA et al., 2003).

Mais uma vez nos deparamos com as construções de gênero. Da mulher espera-se uma atitude de passividade. "A primeira experiência sexual tende a se dar de forma desprotegida em razão da persistência dessas definições de papéis de gênero, na qual esperase de uma mulher um comportamento passivo e do homem um comportamento ativo" (PATONJA, 2002. TORRES, 1998, p. 5339)

No decorrer do tempo e com as transformações sócio-culturais as diferenças sexuais foram se tornando mais latentes, por tanto tem raízes históricas, ao passo que Engels (2009, p. 85) considera que "a primeira oposição de classe que apareceu na história coincide com o desenvolvimento do antagonismo entre o homem e a mulher, na monogamia e que a primeira opressão de classe coincide com a opressão do sexo feminino pelo masculino" e mais adiante acrescenta: "Na família, o homem é o burguês e a mulher representa o proletário." (2009, p. 95). São constituídas a medida que a sociedade se organiza, que o Estado e a propriedade privada se forma. Nesse caminho, as diferenças sociais entre mulheres e homens seriam construídas no plano da cultura e não da natureza.

Para Saffioti (2004) gênero seria a construção social do masculino e do feminino. Em SCOTT (in PEDRO, 2005) gênero é a organização social da diferença sexual. Não se trata de ignorar as diferenças biológicas entre homens e mulheres, contudo a percepção de que essas diferenças não podem legitimar as disparidades que assistimos ao longo dos séculos.

Investigando o uso de gênero, como um conceito, Pedro entende que este nasce de uma necessidade real, no seio do movimento feminista da década de 80 :

Justamente pelo fato de que as palavras na maioria das línguas têm gênero mas não têm sexo, que o movimento feminista e de mulheres, nos anos oitenta, passaram a usar esta palavra "gênero" no lugar de sexo. Buscavam, desta forma, reforçar a idéia de que as diferenças que se constatava nos comportamentos de homens e mulheres não eram dependentes do "sexo" como questão biológica, mas sim eram definidos pelo "gênero" e, por tanto, ligadas à cultura. (PEDRO, 2005, p. 78)

“Agir no espaço público não é fácil para as mulheres, dedicadas ao domínio privado, criticadas logo que se mostram ou falam mais alto." (PERROT, 2007, p. 146). Essa subordinação da mulher aos espaços privados tornou a sua atuação pública desencorajada. "A dissimetria do vocabulário ilustra esses desafios; homem público é uma honra; mulher pública é uma vergonha, mulher da rua, do trottoir, do bordel." (PERROT, 2007. p. 136).

Isso agravaria o que a literatura vem caracterizando como 'feminização da pobreza', sentida especialmente nos domicílios chefiados por mulheres, onde estas acumulam funções que vão desde o cuidado com os filhos, afazeres domésticos e atividade laboral remunerada.

De certo, o fenômeno de "feminização da pobreza" já ganha espaços sem fronteiras ao ser confirmado não só nas estatísticas das principais agências internacionais, como também no cotidiano, nas imagens de países com desenvolvimento humano baixo. Posto isso, pode-se afirmar que, no conjunto dos indivíduos que vivem com menos de um dólar por dia, a maioria é constituída de mulheres. Mas é fundamental que se frise sempre, em primeiro lugar, a questão da trajetória feminina da escola ao mundo do trabalho, pois é através deste mecanismo que se proporciona a autonomia necessária, sobretudo financeira, para a condição de mulher não seja mais motivo de vitimização, submissão ou invisibilidade. (CAVALCANTI, 2005, p. 94)

No entanto, essas mulheres circulam, se movimentam, atuam, interagem e militam. Encontram nos movimentos sociais possibilidades de suprir suas demandas materiais, mas a medida que tentam transformar uma realidade também se transformam. Isso explicaria, por exemplo, a composição do Movimento dos Sem Teto da Bahia, no qual as mulheres representam cerca de $70 \%$ dos participantes.

Helaine Pereira Souza 


\section{O que Significa ser Sem Teto?}

Uma ocupação no bairro de Mussurunga resultará na fundação do Movimento Sem Teto de Salvador. Segundo Cloux (2008), outros terrenos estavam sendo ocupados por diferentes grupos no mesmo bairro. Esses grupos acabaram estabelecendo contatos.

A primeira ocupação do Movimento acontece em um terreno da Estrada Velha do Aeroporto, com aproximadamente $3 \mathrm{~km}$ quadrados, chamado 'Dois de Julho', seguia os modelos de acampamento do Movimento dos Trabalhadores Rurais Sem Terra (MST). No mesmo mês, a Superintendência de Controle e Uso do Solo (SUCOM) articula uma tentativa frustrada de reintegração de posse. Sem êxito dado à inexistência de um mandato judicial. A segunda tentativa é efetivada e desloca 700 cadastrados. A reintegração leva o movimento a ocupar as páginas dos jornais baianos. Daí em diante a mobilização popular irá se tornar cada vez maior.

A partir de então o MSTS, que depois com a expansão para outros municípios baianos passará a adotar a sigla MSTB (Movimento dos Sem Tetos da Bahia), realiza uma série de ocupações, recebendo ampla cobertura midiática e se tornado um dos movimentos de maior visibilidade no cenário baiano.

Para o Movimento, sem teto são todos aqueles que "vivem de favor, já constituíram um núcleo familiar e que são obrigadas a morar de favor, por não ter condições de pagar aluguel e ter sua casa própria, aquelas famílias e pessoas que moram embaixo de pontes ou viadutos. Aqueles que ganham um salário muito baixo e sacrificam sua qualidade de vida pagando aluguel ou aquelas pessoas que vivem em situação de risco." (CARDOSO in PRONZATO, 2004).

Contudo, ainda segundo o MSTB, o objetivo do Movimento vai além da moradia, na medida em que abrangem outras demandas que atingem principalmente as camadas mais desfavorecidas da população:

O MSTB entende que outras necessidades, tais como Saúde, Educação, Lazer, Segurança, Creche, Meio Ambiente, Emprego, etc, fazem parte da LUTA por MORADIA e Reforma Urbana que atenda os interesses dos setores excluídos da sociedade.

(...)

O MSTB é um movimento pela cidadania que parte da comprovação de que para os setores populares esta não existe em nosso país, e procura construir alternativas nesta perspectiva, e compreende que a garantia dos Direitos Humanos, Justiça Social, Solidariedade, Qualidade de Vida e Participação Popular só serão alcançados com a Igualdade Econômica, Política e Social.

O MSTB solidariza-se na LUTA CONTRA TODA FORMA DE OPRESSÃO E EXPLORAÇÃO existente e presta solidariedade aos trabalhadores de todo mundo. O MSTB tem como princípios norteadores a mais ampla Democracia interna, não fazendo distinção entre militante e coordenadores de qualquer instância nas suas relações cotidianas. (Regimento Interno do Movimento do Sem Teto da Bahia/Salvador, 2005)

Por tanto, em seus documentos o Movimento destaca que a luta por moradia seria apenas a ponta iceberg, e entende que essa causa que ultrapassam a contemporaneidade, buscando raízes na história do nosso país, o MSTB se coloca como herdeiro da ausência de políticas sociais que garantissem aos escravos alforriados uma inserção digna e igualitária na sociedade brasileira. Válido salientar que o 'teto' não seria o fim, mas a diminuição dos abismos sociais que estão na formação do povo brasileiro.

Somos sem-teto, mas não apenas, pois a realidade da escravidão pariu a realidade da exclusão, negando-nos trabalho, saúde, segurança pública, educação, espaços de arte e lazer, enfim, condições elementares de vida. Estas questões são, portanto, reivindicações legítimas do MSTB. Referenciando-nos na luta pela conquista de uma sociedade que seja capaz de efetivar de maneira profunda as liberdades política, econômica e social, cultura e religiosa, buscamos não apenas um "teto" particular, mas sim a constituição de "comunidades de bem viver". Empunhando a bandeira da Reforma Urbana, ao fundo afirmamos a força de relações sociais baseadas em idéias de liberdade e não da negação dos direitos de milhões. (Documento Quem Somos, 2005)

Séculos de exclusão que são reapropriados e ganham novos sentido, à medida que os integrantes não vêem suas demandas como causa isolada, mas integrante de uma realidade maior, que não minoria,

Helaine Pereira Souza 
mas que se aproximam de outras demandas.

Muitas são as possibilidades de inspiração ideológica do MSTB, se considerarmos a história de luta de nosso povo. Das primeiras revoltas indígenas e formação de mocambos, passando pela Conspiração dos Alfaiates, pelo 2 de Julho, pela resistência do Quilombo do Urubu, da Revolta dos Malês, da Sabinada e da Luta de Canudos, os sonhos de liberdade dos oprimidos da Bahia irromperam pelos mais diversos momentos de sua trajetória. A reflexão sobre o significado destes processos constitui uma das mais promissoras formas de construção identitária de nosso Movimento. (Documento Quem Somos, 2005,)

O objetivo central do MSTB seria a constituição da Comunidade de Bem Viver, descritas pelo coordenador Pedro Cardoso como:

Comunidades que mesmo dentro dos limites do capitalismo construam uma contrahegemonia no sentido de valores e ações que apontem para uma ruptura e construção de um projeto socialista. Então o objetivo é o resgate histórico-cultural de iniciativas socialistas e de construção de comunidades que se contraponham ao sistema capitalista. O fomento de valores como o ecumenismo, o cooperativismo, o associativismo e a vivência coletiva são elementos norteadores de nossa ação. (CLOUX, 2008, p.58)

Não é raro perceber a apropriação do Artigo $6^{\circ}$ da nossa Carta Magna por parte dos integrantes do MSTB, esse artigo, em especifico diz que "São direitos sociais a educação, a saúde, o trabalho, a moradia, o lazer, a segurança, a previdência social, a proteção à maternidade e à infância, a assistência aos desamparados" (grifo nosso. BRASIL, 2003). Entretanto essa mesma Constituição, no Artigo $5^{\circ}$, assinala o direito da propriedade, se esta possui função social, este conceito já retira o direito à propriedade em caráter absoluto.

Outro elemento que desperta grande atenção na composição do Movimento aqui estudado é grande concentração de mulheres, estas somam quase $70 \%$ dos integrantes do MSTB. Dentro da dinâmica do Movimento, elas são consideradas "fixas" enquanto os homens nem sempre, isso é explicitado pelos cadastros realizados, a posse da casa, no momento da conquista, é preferencialmente da mulher, ao menos quês esta não assim deseje.

São elas:

Herdeira de um legado de pobreza, mas também de ousadia e esperança, pela sua condição de gênero, raça e classe, a presença feminina, em sua grande maioria negra, mostra imensa expressão nas ocupações, núcleos e nas manifestações de rua promovidas pelo Movimento. A saída do âmbito doméstico e a inserção na política, seja nos cargos de direção, seja participando das ocupações, traz novas possibilidades para as mulheres do MSTB, que passam a se familiarizar com o público das ruas e dos espaços de poder, ao tempo em que podem vir a questionar o que acontece entre quatro paredes, a exemplo das divisões do trabalho doméstico com marido e filhos. Por tudo isso, constituem fortes referências para a construção das COMUNIDADES DE BEM VIVER baseadas em relações de gênero igualitárias. (Documento Quem Somos, 2005)

No ano de 2005 é inaugurando, dentro do MSTB, um coletivo de mulheres, intitulado Guerreiras Sem Teto. A participação em um movimento social, dota essa mulher de um grau de empoderamento, a medida que ela já não ocupa apenas as esferas domésticas, mas passa a ter uma atuação no âmbito pública, desde os primórdios do movimento elas ocupam cargos de coordenação e estão presentes nas caminhadas, assembléias e outras atividades realizadas (CLOUX, 2008).

Essas mulheres entendem que suas histórias de vida não estão desvinculadas. Que fatores como classe e raça soma-se a categoria gênero, que por longos períodos relegou a mulher a condição do privado, sendo tarefa masculina ocupar os espaços públicos. Resultado de uma sociedade com bases no patriarcado,

Mas, nós, Guerreiras Sem Teto, que somos descendentes daquelas que foram arrancadas de suas famílias, sociedades, culturas, modos de viver na África mulheres que criaram um modo de vida neste continente chamado América -, que nos inspiramos umas nas outras, que nos "seguramos" umas nas outras, das mulheres da Resistência não herdamos apenas as mazelas da "diáspora", mas herdamos sobretudo a coragem, a combatividade, a

Helaine Pereira Souza 
capacidade de organizar a luta pela liberatação do povo negro, como Zeferina, Dandara, Luiza Mahin e tantas outras. Hoje damos continuidade às lutas iniciadas pelas nossas ancestrais. E é inspiradas na luta de muitas guerreiras que vieram antes de nós que avançamos para a organização do nosso trabalho dentro das ocupações, sem nos deixarmos abater com as idas e vindas, sem nos deixarmos abater pela falta de perspectiva, sem nos deixarmos abater pelos problemas próprios de nosso difícil dia à dia. Hoje, com a força de mais companheiras que levantam a bandeira da libertação das mulheres e do combate à todo tipo de discriminação e opressão de gênero, avançamos para a construção da rede de solidariedade entre nós, companheiras de/na luta, para a construção dos núcleos de base, para a construção do Coletivo das Guerreiras Sem Teto e gênero, para a construção da nossa liberdade!!! (grifo original. Documento Guerreiras Sem Teto Histórico, 2008)

O Regimento Interno Movimento dos Sem Teto da Bahia é o documento que define a missão, os princípios e as condutas a serem adotadas por todos os integrantes, foi aprovado em 2005 no 'I Congresso do Movimento dos Sem Teto de Salvador'.

Posicionamentos que constam no Regimento Interno Movimento dos Sem Teto da Bahia garantem igualdade étnica, social e de gênero, o que esta em consonância com documentos elaborados internacionalmente, na busca pelo enfrentamento a qualquer tipo de discriminação:

\section{ART. 12.}

Todos os filiados são iguais, independente de condição social, raça, gênero, opção sexual, credo religioso, não sendo permitido o privilégio de qualquer um, seja ele militante de núcleo, ocupação ou qualquer instância de direção do Movimento.

O Regimento também indica possíveis sanções aqueles que violarem tais normais da convivência:

\section{ART. 22}

Será passível de expulsão do Movimento o filiado que cometer roubo, estupro, espancamento, particularmente contra mulheres e crianças, homicídio, uso e tráfico de drogas, usar indevidamente o nome do
Movimento ou quaisquer outros crimes que tragam problemas para este.

As mulheres Sem Teto são vêem remodelando sua participação no cenário urbano soteropolitano. Resignificam suas demandas privadas atuando no espaço público, muitas impulsionadas pela maternidade.

\section{Entre a Impermanência da Idade e a Permanência de seu Sexo ${ }^{3}$}

No primeiro semestre de 2010, percorremos as ocupações do MSTB na capital baiana, a fim de entrevistar jovens mulheres, entre 19 a 24 anos, que durante a adolescência passaram pela experiência da maternidade. $\mathrm{O}$ recorte se justifica pelo grande participação feminina no referido movimento, pela experiência da martenagem como balizador das expectativas de futuro e modelador das relações cotidianas, e nesse rol insere-se a visualização da própria sexualidade.

Para tanto, realizamos entrevistas em profundidades nas ocupações onde as jovens residem, a participação se de deu de maneira voluntária e com a indicação do/a coordenador/a local, as jovens assinaram o termo de livre consentimento, com o auxilio de um gravador, as entrevistas foram gravadas, e em seguida sistematizadas. Um segundo instrumento, foi um questionário socioeconômico, que nos possibilitou traçar um perfil das entrevistadas.

As atrizes da nossa pesquisa têm histórias de vidas diferentes, um cotidiano marcado por lutas e resistência, experiências e vivências que em muito modela suas identidades individuais e coletivas. Em comum, talvez, apenas o evento da gravidez, no período da adolescência e a participação no MSTB local de moradia e atuação -, e mesmo esta pode ocorrer de maneiras distintas. Por tanto, optamos em singularizá-las, dando-lhes nomes para preservar identidades. Cronologicamente, há uma distância entre a nossa entrevista e o momento da gestação, o que permite a estas jovens reflexões sobre si mesmas e sobre o vivido.

Rosa, dezoito anos, mãe de duas crianças, a primeira aos quatorze anos

Violeta foi mãe aos dezoito anos, atuante está com dezenove anos.

Girassol tem vinte e dois anos, mãe de um menino aos dezesseis anos.

Lírio é mãe de quatro meninas, provenientes de duas uniões, a primeira gestação aos

Helaine Pereira Souza 
quinze anos, e a última há poucos meses.

Três entrevistadas estavam estudando no momento da gravidez, entretanto nenhuma delas chegou a concluir o ensino básico. O abandono escolar é uma realidade, muitas vezes justificada impossibilidade momentânea, e por tanto, haveria um retorno futuro aos estudos. Sem exceção, essas jovens mulheres se dedicam ao trabalho doméstico, no entanto revelam não estarem trabalhando, desconsideram a atuação no serviço de casa como atividade formal, "naturalizando" o cuidado e desconsiderando a economia que este requer como relevante.

Dificilmente, a renda familiar atinge o valor de um salário mínimo, que neste momento equivale a quinhentos e dez reais. Majoritariamente, os rendimentos são atingidos pelo trabalho informal, que se caracterizam com atividades como mariscagem, coleta de resíduos sólidos e vendedores ambulantes. Porem, entre os auxílios governamentais só foram localizadas as inscrições junto ao Bolsa Família. Ainda assim, somente uma entrevistada o recebia.

Para o item 'Raça/etnia/cor' nos valemos do padrão utilizado pelo Movimento em instrumentos de cadastro. Todas as entrevistadas se auto-declararam negras.

Na base do MSTB, é possível visualizar, em termos de religião, uma maioria protestante. $\mathrm{Na}$ nossa pesquisa não foi diferente, entre as protestantes, todas se declaram pentecostais. O que, talvez, reforçasse as dificuldades de falar sobre sexualidade no âmbito familiar.

O tema da sexualidade não é um assunto 'fácil' de ser abordado, quando limites do 'brincar' e da espontaneidade são ultrapassados. No campo da orientação sexual há muitos tabus. Durante nossas entrevistas o que percebemos é que a família não é espaço privilegiado para conversas sobre sexualidade, revelando os abismos entre as gerações, que dificultam os diálogos.

De fato, conversar sobre sexualidade é muito mais do que simplesmente transmitir informações. Requer a transposição de barreiras, como idade e valores, em favor de uma proximidade que facilite a percepção do momento existencial do filho, mediada por mensagens que não sejam nem restritivas e nem permissivas. Implica a formação de uma aliança comunicativa na qual filho ou filha encontre espaço e apoio para o desenvolvimento psicológico.Contudo, muitos pais e filhos não conseguem estabelecer essa condição existencial para o diálogo, principalmente quando o tema é sexualidade. Os pais, quando conseguem abordar o tema, não encontram meios de desvencilhar-se de suas histórias pessoais, às vezes conflituadas, e limitam-se a oferecer ou impor conselhos superficiais. (DIAS e GOMES, 1999, p. 82)

$\mathrm{Na}$ fala das entrevistas,

Minha mãe nunca ligou pra essas coisas, nunca conversou comigo, até um beijo na boca, na televisão, ela mandava fechar o olho pra não ver. Ai quando eu fui descobrir, fui descobrir sozinha. (Lírio)

As jovens revelam não ter esse espaço e que as mães não estavam disponíveis para esse assunto. Contam-nos que por vezes inspiravam medos e receios sobre o corpo, sexo e o exercício da sexualidade. "A comunicação sobre sexualidade entre pais e filhos é marcada, enfim, por uma ambigüidade em que ambas as partes reconhecem o problema, mas evitam enfrentá-lo. O dilema está então constituído" (DIAS e GOMES, 1999, p. 82).

Até quando eu me perdi, me perdi não, que ninguém se perde, eu tive o maior medo de contar a ela." (Girassol).

E completa:

Minha mãe é muito rústica para essas coisas. Ela não parava pra dizer assim "não minha filha, é desse jeito". Ela ensinava de um jeito mais rústico, do jeito que ela aprendeu. "Ah se você ficar ai fazendo, você engravidar, você vai ver." (simulando a voz da mãe aos gritos). Era assim que ela ensinava, entendeu? Não era de sentar conversar. (Girassol)

Nas escolas, eventualmente, havia palestras sobre Doenças Sexualmente Transmissíveis e métodos anticoncepcionais. Ainda assim, destinada a alguns ciclos, o que nos sugere que a educação sexual se inicia tarde, se tomarmos como indicador a iniciação sexual cada vez mais cedo e as freqüentes repetências, que distanciam séries escolares e idade das adolescentes para o processo regular.

Na escola eu só vim aprender sobre isso quando já tinha a outra filha, porque quando eu engravidei, eu tinha 15 anos, e

Helaine Pereira Souza 
tava na quinta série e ainda não dava orientação sexual, não. Veio dar agora que eu passei para sétima, oitava. (Lírio)

Esse tema, quando encontravam espaços nas escolas, eram apenas as aulas de Ciências que tinham orientação sexual no currículo, lembram as que alcançaram um nível um pouco maior de escolaridade.

A professora não falava disso, não. Só quando era aula de ciências que elas davam isso ai. (Rosa).

Nossas entrevistadas revelam ter conhecimento das Doenças Sexualmente Transmissíveis e as formas de contágio. Entretanto, não era uma preocupação presente, ainda prevalecendo a idéia de contracepção desnecessária a medida que se estabelecem vínculos. É como se o compromisso, o amor ou mesmo o namoro imunizasse os indivíduos de qualquer DST, e de igual modo a possibilidade de uma gravidez precoce não é enfrentada.

Eu não era essas mulheres de tá com um e outro, não. Eu me prevenia assim com camisinha, de vez enquanto. $O$ único que eu não uso camisinha é com meu marido agora, que já tem quatro anos com ele. (Violeta).

Ou ainda,

Em nenhum momento eu tive medo, porque assim, o pai do meu filho foram quatro anos, eu e ele, longo nos primeiros anos a gente com camisinha direto, e depois que passou um ano e pouco, ai eu já confiava nele, a gente passou a ir sem camisinha. (Girassol).

Lírio é uma exceção.

Tive medo (contrair DSTs) porque meu primeiro marido, é o pai das duas primeiras, as duas ultimas é outro esposo, o pai delas, era muito assim, mulherengo, ai eu tinha medo sim." (Lírio).

Sobre os métodos contraceptivos, Lírio conta-nos que inicialmente só conhecia o preservativo masculino e amplia seus conhecimentos quando passa a freqüentar postos de saúde. Rosa diz que mesmo conhecendo, o uso não lhe agradava.

Percebemos algumas concepções distorcidas, sobre os métodos e o acesso aos mesmos.

Conhecia os métodos anticoncepcionais, mas não tinha idade de ir no posto pegar, porque até hoje se você pega uma menina de 16 anos a 15 e leva pra um ginecologista pra passar um anticoncepcional ele não vai passar nunca. Ele vai dizer que tá muito novo, que tá muito cedo, que não pode, que porque organismo. O organismo de uma menina de 15 anos não é assim tão desenvolvido pra tomar um anticoncepcional, ele nunca passa. (Girassol)

E mais adiante completa,

Eu ia direto, eu sempre fui, sempre gostei de ir ao ginecologista, mas eu mesmo, nem perguntava, porque sabia que ele não ia me dar. Como qualquer dessas meninas da nossa ocupação com 15, 14, 13 ou 12 que muitas iniciam sua vida sexual mais cedo dos que as outras, eu esperei chegar aos 15, mas têm muitas que ao esperam chegar, se as mães saírem pra procurar, levar elas pra tomarem um anticoncepcional, eles nunca vão dar. (Girassol)

De certo, como aponta a literatura, jovens aprendem com outros jovens. A socialização toma uma importância singular nessa fase da vida. Entretanto, nossas entrevistadas revelam que não havia outras colegas grávidas, no momento de suas gestações,

As colegas não influenciaram, não conhecia ninguém grávida. (Lírio).

Nenhuma delas engravidou tão cedo, quanto eu. Hoje engravidaram, depois, e tiveram bem mais filhos do que eu. Mas eu que engravideis mais cedo do que elas. (Girassol).

As confissões entre adolescentes, também, são negadas. Afirmam que assuntos como sexualidade, não são freqüentes,

Tinha uma colega só, especificamente, que sempre falava uma coisa ou outra. (Girassol)

Após a descoberta da gravidez neste período, mudam as relações com os amigos e pessoas

Helaine Pereira Souza 
próximas. $\mathrm{O}$ que as adolescentes avaliam com muito pesar.

A maioria das minhas colegas já não andava comigo. Teve umas que criticaram muito. Por ser muito novo. Por tá muito novo. Pouca idade. Por que você vai engravidar com essa idade, menina? Muitas se afastaram. Foi muito ruim. (Girassol).

Eu sai com minha colegas, depois me deixaram de lado, ninguém ia na minha casa me visitar, e eu também fiquei muito nervosa e colocava todo mundo pra correr. Ai as meninas parou de ficar com amizade, assim, me procurar, se distanciou um pouco. Ai depois que eu ganhei neném, começou a amizade tudo de novo. No momento eu não me senti sozinha, porque assim, eu tive uma gravidez muito enjoada, eu tive enjoou de tudo e todo mundo eu não queria nem ver gente. (Lírio)

No momento que se vêem grávidas precocemente, descobre-se que já não se tem as amizades antigas. A partir desse processo, haverá uma tentativa de construir novos grupos.

Eu tentei conciliar gravidez com estudar pra vê se ocupava a mente um pouco. Fui estudando. No colégio fiz outras amizades. (Girassol).

Essas novas amizades podem dedicar mais atenção, partilhar os momentos da gravidez, com certo entusiasmo, mas amigas do tempo de brincar junto, essas já não estão presentes. Os projetos individuais são modificados, novas demandas se inserem, novas perspectivas são criadas e novos objetivos são galgados.

Me abalou, porque assim, eu engravidei e
no momento que eu precisava de alguém
pra desabafar, poxa, não tinha ninguém,
não tinha ninguém. Todo mundo sumiu, e eu
tinha muitas amigas de sair de festa e tal.
Mas na hora que eu tava grávida não tinha
ninguém. Me vi sozinha, sozinha, sozinha.
(Girassol)

Todas as mães aqui apresentadas se auto-definem como jovens. Conceito esse, relacionado à faixa etária, e que não mudaria em função da maternidade.
Eu me acho jovem, mas minha mente já é de adulta. Não é só porque eu tenho um filho que vou ser senhora já. Não! (Rosa).

Me considero jovem, por causa da minha idade. Não é porque tenho um filho que vou deixar de ser jovem. (Violeta).

Sim, tenho 22 anos só. Não me considero velha não. Sou jovem. (Girassol).

Entretanto, conceituar juventude não é tarefa simples, a literatura nos aponta o mesmo. A idéia de ser jovem, como tempo de ter amigos, de diversão, confrontaria com as responsabilidades que a maternidade trás.

Ser jovem é um negocio enfocado. né (risos). Boa pergunta. Ser jovem é ter outros jovens para sair. Ser jovem é curtir a sua vida. É muito show, muita paquera. Essa era a minha juventude, antes de engravidar. Agora é diferente, eu tenho meu filho, tenho meu esposo que não é o pai do meu filho. Tenho uma casa pra cuidar. Tenho minhas responsabilidades. Tenho sempre que tá trabalhando, fazendo bico pra sustentar meu filho. Mudou muita coisa. (Girassol)

A maternidade pode, ainda, subtrair o tempo da infância,

Eu me sinto uma criança, uma adolescente, ainda, porque eu perdi, né, minha adolescência toda, que eu ainda brincava de boneca, ai eu engravidei, ai ficou tudo pra trás, hoje eu fico tentando fazer coisas que era pra ter feito há muito tempo atrás, eu brinco com minhas filhas. É tanto que parece que sou irmã delas, falo nem parece que eu tô falando. (Lírio)

Mesmo com os percalços de uma gravidez precoce, elas nos revelam o desejo de ser mãe, ainda que não exatamente no período em que ocorreu. Reforçando as construções de gênero, que estabeleceriam que a mulher esta para a maternidade.

Tinha vontade de ser mãe, mas não nessa idade." (Rosa).

Ou ainda,

Eu não pensava em ser mãe tão cedo, 
porque eu nem sabia cuidar do menino, quando nasceu, para mim era a mesma coisa de tá brincando com boneca. (Girassol).

Apresentam-nos uma noção de fatalismo, como se não houvesse alternativas e a opção de não engravidar. Sendo assim, seria a maternidade fim de todas as mulheres?

Querer ninguém, quer engravidar. Ninguém engravida porque quer." (Girassol).

E da ausência de perspectiva. Afinal, são jovens em condições extremas de vulnerabilidade, aos quais o futuro é plantado em terrenos de incertezas.

Eu me arrependi muito, sabe? Depois que eu vim pegar amor a meи filho que eu deixei, mas me arrependia muito de ter engravidado cedo. Eu pensava que nada ia dar certo na minha vida. Não vinha assim, de eu pensar, que depois desse filho ia melhorar. Eu pensava só desespero. Eu pensava isso. (Rosa)

Violeta, diferente das outras jovens, aponta o desejo de ser mãe,

Eu sempre quis ter filho, mas só consegui agora, com 18 anos, eu vinha tentando desde os 16 anos. (Violeta)

A possibilidade do aborto aparece, e por vezes há tentativas:

Nisso ai (aborto) eu pensei muito. Depois eu não consegui, eu deixei, né. Eu tomei chá. (Rosa).

No entanto ela é desencorajada e as decisões por mais individuais que pareçam, são compartilhadas e divididas com o coletivo, seja entre familiares como entre amigos.

Só que ai veio medo e também conselhos. Muitas pessoas vieram falar "ah se você tomar remédio, ou alguma coisa sua criança pode nascer com problemas ou então você pode vir a falecer junto com a criança, porque na hora que eu vim descobrir q tava grávida, eu já tava com cinco meses. (Lírio)

Concepções religiosas marcam esta decisão, mesmo em casos com o de Girassol, que nos revela não ter religião.

Até um certo momento eu pensei em tirar, mas depois eu não tive coragem. É um pecado que eu não vou levar nunca na minha vida. (Girassol)

Nossas depoentes revelam que o corpo e a reprodução são lócus para reflexões conflituosas e paradoxais. Deste modo, novamente, Violeta, a que confirma a exceção, salienta que nunca pensou na possibilidade de aborto, uma vez que já vinha tentando a gravidez há pelo menos dois anos.

Admite-se que a gravidez modifica a vida. Transforma as relações sociais e determina os espaços de socialização. Aparece a 'obrigação de ficar em casa' (Rosa).

Mudou tudo na minha cabeça, antes eu não pensava em nada, agora tenho que pensar primeiro nos meus filhos. E - Eu não saiu, assim não, porque agora eu tenho meus filhos (Rosa).

Para Violeta, não há grande mudanças.

Já não era muito de curtir, era caseira. Só fazia trabalhar, mesmo. vinha só nos finais de semana, então para mim não importava. (Violeta)

Cuidar dos filhos é uma habilidade que vai se adquirindo com o tempo.

Fui aprendendo aos poucos, é muita coisa, você cuidar de uma criança é muito difícil, você pensa que é tão fácil assim, tinha ajuda sim, tinha a mulher do meu pai, que é minha madrasta, que me explicava assim, como era e tal, fui aprendendo, né. $\mathrm{Na}$ tora. (Girassol)

Para o futuro, essas jovens fazem planos, sonham. Mas não desejam mais uma maternidade.

Espera que seja a única (gravidez) (Violeta);

Não quero filho mais nenhum. (Girassol).

E admitem que a vida poderia ser outra, não fosse a gravidez precoce.

Eu tinha certeza, porque com 15 anos já 
tava na oitava série, eи queria ser uma boa profissional, pensava até em fazer faculdade. (Girassol).

Girassol completa dizendo,

Não me arrependo de ter tido meu filho, jamais, isso ai eu não me arrependo nunca, mas eu me arrependo das coisas que eu perdi por ter engravidado dele. Que ai foi passando o tempo, eu não consegui concluir meus estudos, porque sempre eu tinha ele, no colégio que eu estudava eu ia de calça apertada direito, ai chegou um momento que a barriga já tava grande, $e$ eu não podia ir mais, o diretor não liberava ir com outra bermuda, mas folgada e tal. E até hoje eu não consegui concluir minha oitava serie. Tinha outros projetos pra minha vida, podia tá num emprego melhor, com uma vida melhor. Agora hoje, com a minha cabeça que eu tenho, eu não teria engravidado de ninguém. Não seria mãe, porque eu sinto muita falta de dos meus 15 anos porque eu curtia muito, saia muito, me divertia muito, e ate meu filho ficar nessa idade, foi um tempo de minha vida que parou. Porque eu nunca confiei deixar meu filho com ninguém, fica medo de alguém maltratar, foram cinco anos de minha vida que parou, ai depois de cinco anos, mesmo com meus 22 anos, aquele pique que eu tinha com 15 eu já não tenho mais com 22. Sou mais de ficar em casa. Hoje, fica complicado, você fazer, quando você tem um filho, porque as únicas faculdades que a gente pode fazer é a publica, né. E minha irmã, ela fez faculdade pela UFBA, minha irmã estudava o dia todo, mas ela podia porque ela não tinha filho nenhum, e eu não posso estudar o dia todo, por que eu preciso ter uma renda pra sustentar meu filho. Então meu sonho da faculdade fica mais complicado. Fica mais pra frente. (Girassol)

Nesses planos para o futuro encontra-se a militância no MSTB. Mapeamos distintas formas de participar do Movimento, jovem que ocupam a Coordenação local de sua ocupação, e outras que alegam não terem tempo de ir às caminhadas.

Apenas Lírio afirma que conheceu o Movimento através de uma vizinha, quando ainda morava com a mãe e com o companheiro. E que esta aconselhou que ela procurasse a ocupação. As demais conheceram o MSTB através de suas mães, que passaram a integrar o movimento e assim, trazem outros membros da família. Violeta e Rosa, são irmãs, participam do MSTB há quatro anos, quando a mãe trouxe a família.

O principal objetivo dessas jovens é obtenção da casa própria.

Espero conseguir minha moradia digna. (Violeta).

Todas elas dizem participar das atividades do Movimento, mas revelam a distância entre a base do MSTB e a Coordenação e os documentos produzidos, não percebemos apropriação de .conceitos com gênero, patriarcado, estado machista (Ver trecho do documentos "Guerreiras Sem Tetos")

Nas reuniões, festas juninas, passeatas.
(Rosa);
Quando tenho tempo, vou à passeata.
(Lírio);
Participo quando posso de palestra,
reuniões" (Violeta).

Há, também, as que visualizam no MSTB perspectiva não apenas para modificar sua vida, mas colaborar para relações sociais mais democráticas. Visto que os moradores das ocupações são, muitas vezes, marginalizados.

Sou coordenadora local do movimento. Eu me elegi no domingo passado. Eu me elegi agora, então a gente não teve tempo de fazer nada. Mas a gente tem um trabalho muito bacana pra realizar na nossa comunidade. Porque assim, a gente quer botar um trabalho de conscientização, porque a gente que mora do lado de cá é muito marginalizado pelo pessoal do lado de lá. Eles entendem que por morar na favela só tem ladrão, só tem maconheiro, só tem o que não presta. Então a gente ta com esse plano de fazer esse trabalho, porque o pessoal do lado de lá, como a gente chama o pessoal do asfalto passe a olhar mais pela gente, a gente ser tratado igualmente, em qualquer lugar que a gente chegar. É muita diferença de lá pra cá. Eles marginalizam muito a gente. Em todo lugar tem sua parte de marginais, como aqui pode ter um marginal, lá também onde eles moram no prédio deles, também deve ter. Só que eles

Helaine Pereira Souza 
olham pra gente muito diferente, então a gente quer fazer esse trabalho, pra gente fazer uma conscientização, pra eles olhar a gente diferente. (Girassol)

Nossas entrevistadas revelam que suas gestações foram resultado de relações estáveis, ao contrário da máxima que atribui a sexualidade juvenil irresponsabilidade, e relações casuais. Rieth (2002) afirma que as jovens elegem namorados para suas iniciações sexuais e que o ficar não significa práticas sexuais. No geral, o evento da gravidez neste período resultou numa coabitação:

\section{Moro com ele [pai da criança] (Rosa).}

Entretanto, não é o suficiente para que esta se mantenha nos anos que seguem. Algumas das jovens já se encontravam em uma segunda união estável. Mesmo que os jovens não estabeleçam uma união e que passem a morar no mesmo local, isso não significa o fim do namoro.

No começo, ele (o pai da criança) ajudava, todo dia ele ia ver, toda hora ele tava perto, todo dia tava perto, todo dia tava perto, todo dia tava perto, só que foi aquela coisa, quando eu engravidei de meu filho, ele tinha outras mulheres, então a gente não tinha aquele contato, ai quando ele nasceu, ele queria tentar de novo uma vida junta, só que eu não queria mais, porque na hora que eu queria ele perto de mim ele nunca podia estar, depois que meu filho nasceu por que eu ia querer? Ai me retei e não quis mais. (Lírio)

Estar grávida na adolescência não significa ter engravidado de um adolescente, no geral o genitor é mais velho do que a adolescente, o que não necessariamente nos leva a concluir que não se refere a um pai também jovem.

Ele [pai da criança] não ficou tão feliz, mas teve que aceitar. Ele não tinha planos de ter filhos com 23 anos. (Violeta).

Apenas Girassol no revela que o pai da criança ainda estudava no momento em que descobriram a gestação, todos os demais já não freqüentava a escola, Rosa conta que, o genitor, com que coabita atualmente, está desempregado, estudou até a terceira série do ensino fundamental $\mathrm{I}$, e é vendedor ambulante no transporte coletivo urbano. 'Ele vende amendoim'
(Rosa).

A história de Lírio ilustra uma realidade marcada pela violência doméstica. Seu companheiro era usuário de drogas,

O pai delas foi uma pessoa muito agressiva, depois que eu engravidei dela, depois que ela tinha uns sete a oito meses, eu passei a morar com ele, ai depois que eu passei a morar com ele, começou as agressões, ele me agredia verbalmente, fisicamente. Ele me agredia, ai depois eu me separei dele, Fui morar com minha mãe, novamente, e quando eu fui morar com minha mãe eu já estava grávida da outra. Porque já a segunda gravidez, foi uma gravidez que eu tive, mas só que foi uma gravidez quase forçada, porque eu não queria ter nada com ele, mas ele me agredia, me forçava a fazer o que eu não queria, e ai eu acabei engravidando dela. (Lírio)

À figura masculina é destinada a tarefa de prover, do sustento da família, não estando ligada ao cuidado com a criança. Sob o argumento de ocupar o espaço da rua.

"Ele é pintor automotivo, trabalha, só chega a noite.” (Violeta).

As construções de gênero marcam as trajetórias individuais e modelam as relações que são estabelecidas. No entanto, não se pode afirmar que as jovens mulheres que entrevistamos são apenas uma juventude vulnerável, por mais que seja uma população vulnerabilizada, elas encontram na atuação/participação em um movimento social a possibilidade de modificar suas histórias de vida.

\section{Distantes de Uma Conclusão...}

Temáticas como a da juventude alertam para o cruzamento de diversas categorias que precisam ser analisadas. Sejam na exaltação, ou tomada como "problema social", as concepções estão de acordo com determinados tempos e espaços.

O presente estudo investigou como mulheres de um determinado movimento social visualizam suas trajetórias marcadas por uma gravidez na adolescência. Elas compreendem suas historias de vidas não estão isoladas de um contexto mais amplo.

É possível perceber nitidamente as demarcações 
de gênero e os espaços que homens e mulheres 'devem' ocupar, mesmo que a sua militância em si já seja um ato de subversão, o que confirmaria que as diferenças sexuais foram plantadas e enraizadas na sociedade.

Referimo-nos ao uma população vulnerabilizada, posta a margem da sociedade e por tanto, foi sensível a dificuldade de acesso a educação formal e políticas públicas que possibilitassem a essas jovens outras oportunidades. No entanto, a gravidez não pode ser entendida como a materialização da ausência de perspectiva, muito antes ela pode apontar para o projeto, um desejo a longo prazo.

1 Dentre tantas definições, optaremos pela da Organização Mundial da Saúde (WHO, 2001) que classifica a gravidez na adolescência como aquela que ocorre entre os 10 e os 20 anos incompletos

2 O 'ficar' seria uma relação sem maiores compromissos, como fidelidade, e pode ser entendido como um passo que antecede o namoro ou outra forma de compromisso.

3 Menção a citação do historiador Eric Hobsbawm, em Era dos Extremos.

\section{Referências}

ABRAMOVAY, Miriam; CASTRO, Mary; SILVA, Lorena Bernadete. Juventude e sexualidade. UNESCO, Brasil, 2004.

ABRAMOVAY, Miriam; CASTRO, Mary. Juventude, violência e vulnerabilidade social na América Latina: Desafios para políticas públicas. Brasília: UNESCO, BID, 2002.

ALMEIDA, Maria da Conceição Chagas; AQUINO, Estela Maria Leão de; GAFFIKIN, Lynne; MAGNANI, Robert J. Uso de contracepção por adolescentes de escolas públicas na Bahia. Revista de Saúde Pública / Journal of Public Health, São Paulo, v. 37, n. 5, p. 566 - 575, 2003. Disponível em: $<$

http://www.scielo.br/scielo.php?script=sci_arttext\&pi $\mathrm{d}=\mathrm{S} 0034-$

$89102003000500004 \& \operatorname{lng}=$ pt\&nrm=iso\&tlng=pt >

Acesso em: 20 dez. 2009

BORGES, Ana Luiza Vilela; SCHOR, Néia. Início da vida sexual na adolescência e relações de gênero: um estudo transversal, São Paulo, Brasil- 2002. Cadernos de Saúde Pública (FIOCRUZ), Rio de Janeiro, v. 21, n. 2, p. 499 - 507, 2005. Disponível em: < http://www.scielo.br/scielo.php?script=sci_arttext\&p $\mathrm{id}=\mathrm{S} 0102$ -

$311 X 2007000100024 \& \operatorname{lng}=$ pt\&nrm=iso\&tlng=pt > Acesso em: 20 dez. 2009

CABRAL, Cristiane S. Contracepção e gravidez na adolescência na perspectiva de jovens pais de uma comunidade favelada do Rio de Janeiro. Cadernos de Saúde Pública (FIOCRUZ), Rio de Janeiro, vol. 19, no. 2, p. S283-S292, 2003. Disponível em: < http://www.scielo.br/pdf/csp/v19s2/a10v19s2.pdf > Acesso em: 20 dez. 2009

CASTRO, Mary Garcia.; RIBEIRO, Ingrid; BUSSON, Shayana. Norma e Cultura: diversificação das infâncias e adolescências na sociedade brasileira contemporânea de acordo com os direitos sexuais e reprodutivos. In: UNGARETTI, Maria América. (Org.). Criança e Adolescente. Direitos, Sexualidades e Reprodução. São Paulo: ABMPChildhood, 2010, vol. 1, p. 61 - 87.

ABRAMOVAY, Miriam; CASTRO, Mary. Quebrando Mitos: Juventude, Participação e Políticas. Brasília: RITLA/CONJUVE, 2009. v. 1. p.298.

CASTRO, Mary. Garcia. Juventudes e Sexualidade. Brasília: UNESCO, 2004.

CHALEM, Elisa; MITSUHIRO, Sandro Sendin; FERRI, Cleusa; BARROS, Marina Carvalho Moraes; GUINSBURG, Ruth; LARANJEIRA, Ronaldo. Gravidez na adolescência: perfil sóciodemográfico e comportamental de uma população da periferia de São Paulo, Brasil. Cadernos de Saúde Pública (FIOCRUZ), vol. 23, p. 177-186, 2007. Disponível em:

http://www.scielo.br/pdf/\%0D/csp/v23n1/18.pdf

CLOUX, Raphael. MSTS: A Trajetória do Movimento dos Sem Teto de Salvador/Bahia. Salvador - BA: Raphael Fontes Cloux, 2008.

DUARTE, Cristina Maria; NASCIMENTO, Vânia Barbosa.; AKERMAN, Marco. Gravidez na adolescência e exclusão social: análise de disparidades intra-urbanas. Revista Panamericana de Salud Pública / Pan American Journal of Public Health, vol. 19, p. 236 - 243, 2006. Disponível em: < http://journal.paho.org/uploads/1147984562.pdf > Acesso em: 20 dez. 2009 
ENGELS, Friedrich. A origem da Família, da Propriedade privada e do Estado. $3^{\text {a }}$ edição. São Paulo: Editora Escala, 2009.

HEILBORN, Maria Luiza; SALEM, Tania; BOZON, Michel; AQUINO, Estela; KNAUTH, Daniela; ROHDEN, Fabíola; VICTORA, Ceres; MCCALLUM, Cecilia; BRANDÃO, Elaine. Aproximações Sócio-antropológicas sobre a Gravidez na Adolescência. Horizontes Antropológicos, Porto Alegre, vol. 8, nº. 17, p. 13 - 45, 2002. Disponível em: < http://www.scielo.br/pdf/ha/v8n17/19074.pdf > Acesso em: 20 dez. 2009

MOTTA, Alda B. Família e gerações: atuação dos idosos hoje. In: BORGES, Ângela. e CASTRO, Mary. Família, gênero e gerações: desafios para as políticas públicas. São Paulo: Paulinas, 2007, p. 111134.

MSTS: Movimento do Sem teto de Salvador. Organizar, Ocupar e Resistir. Carlos Pronzato. Salvador. 2004. 1 DVD (60min.).

PANTOJA, Ana Lídia Nauar. Ser alguém na vida:gravidez/maternidade na adolescência e dinâmica na vida escolar. In: II Seminário Nacional de Metodologia de Pesquisa em Gênero, Sexualidade e Saúde Reprodutiva, Salvador. Salvador: Editora da UFBA, 2002. vol. 1. Disponível em:

http://www.awmueller.com/deposito/grav_adolesc.pdf > Acesso em: 20 dez. 2009

RIETH, Flávia Maria Silva. A Iniciação Sexual na Juventude de Mulheres e Homens. Horizontes Antropológicos, UFRGS, p. 77 - 91, 2002.

SABROZA, Adriane Reis; LEAL, Maria do Carmo; SOUZA, Paulo Roberto; GAMA, Silvana Granado Nogueira. Algumas repercussões emocionais negativas da gravidez precoce em adolescentes do Município do Rio de Janeiro (1999-2001). Cadernos de Saúde Pública (FIOCRUZ), vol. 20, p. S130 S137, 2004. Disponível em: < http:/www.scielo.br/scielo.php?pid=S0102-

311 X2004000700014\&script $=$ sci arttext $>$ Acesso em: 20 dez. 2009

SAFFIOTTI, Heleieth. Gênero, patriarcado, violência. São Paulo: Editora Perseu Abramo, 2004.

VALE, Alexandre Fleming. Antropologia e sexualidade: por um descentramento da enunciação cientifica. Revista Bagoas. No 02, p. 115-132, 2008. Disponível em: < http://www.cchla.ufrn.br/bagoas/v02n02art05_vale.pd f > Acesso em: 9 mai. 2010

VILLELA, Wilza Vieira; DORETO, Daniella. Tech. Sobre a experiência sexual dos jovens. Cadernos de Saúde Pública (FIOCRUZ), vol. 22, p. 2467 - 2472, $2006 . \quad$ Disponível em: http://www.scielosp.org/scielo.php?pid=S0102311X2006001100021\&script $=$ sci_arttext $>$ Acesso em: 20 dez. 2009

Recebido em 25 de agosto de 2010. Aceito em 17 de março de 2011. 